\title{
With Thanks and Gratitude
}

\author{
Henry Buchwald • Nicola Scopinaro
}

Published online: 22 October 2011

(C) Springer Science+Business Media, LLC 2011

At the end of 2011, we will complete our tenure as editorsin-chief of Obesity Surgery. This opportunity to serve has been a high honor, a position of stewardship that we approached with humility and carried out with pleasure.

We were elected editors-in-chief by the governing bodies of the International Federation for Surgery of Obesity and Related Diseases (IFSO) with the mandate to serve IFSO to the best of our abilities, a mandate that includes, but involves far more than, publishing a monthly journal of high-quality scientific articles.

We are dedicated to the bedrock principle of medical publishing: editorial integrity. That integrity entails presenting the whole scientific truth in what receives publication. The seminal requisite in deriving and propagating scientific truths is veracity. Veracity entails telling the whole scientific truth. For example, a report published in the medical literature must credit past discoveries and pertinent findings, including contrary outcomes and opinions. Censorship by silence is, we believe, unacceptable. When each of us becomes a patient, and most of us will, we will wish to be treated by a physician who has been educated on whole truths, not on half-truths.

Similarly, editorial integrity requires encouraging the free expression of novel concepts and ideas that have met the stringent criteria of peer review and inviting further discussion through letters to the editor and follow-up articles. That same integrity compels us to join our colleagues, the editors of respected surgical and medical journals, in the universal belief in the separation of editorial policy and editorial decisions, including control of the

H. Buchwald $(\bowtie) \cdot$ N. Scopinaro

Department of Surgery, University of Minnesota,

420 Delaware Street SE, Mayo Mail Code 290,

Minneapolis, MN 55455, USA

e-mail: buchw001@umn.edu masthead, from matters of business, such as advertisement and circulation, and from ceding those editorial prerogatives we were elected to protect.

Three of our basic goals during our tenure have been: increased national IFSO representation, increased recognition for our international reviewers, and expansion of publication opportunities.

We have considered it our mission to ensure that Obesity Surgery is the voice of the ever-expanding global body of national organizations that constitute IFSO. Currently, IFSO encompasses 51 countries. We are an organization that continues to expand as metabolic/bariatric surgery becomes a dominant discipline worldwide. Thus, the IFSO journal attempts balanced national representation in its monthly table of contents, with special attention given to papers from scientifically emerging nations in our field.

Our intent from the beginning of our stewardship of the journal has been to be inclusive and welcoming to the scientific world that our reviewers, subscribers, and contributors represent. Thus, we have expanded the masthead to 118 associate editors and members. These individuals have often reviewed a submitted manuscript every month. Without these dedicated metabolic/bariatric surgeons, endocrinologists, nutritionists, psychiatrists, psychologists, plastic surgeons, statisticians, cardiologists, lipidologists, hepatologists, radiologists, economists, nurses, and basic scientists, there would be no premier journal competent to feature the entire spectrum of our discipline.

In order to serve the IFSO mission, we attempted to increase the number of Index Medicus-listed publications by expanding online articles, allowing detailed data presentation for select individuals in a non-universal area of interest while publishing papers of more general interest in print, as well as online. This is a model practiced by 
many distinguished journals, but one that we were not permitted to implement in Obesity Surgery.

We owe a special debt of gratitude to our Managing Editor, Deana Rodriguez, whose expertise and goodwill encouraged and educated us in the performance of our task. It has also been a pleasure working with Tracy Marton of Springer Journal
Production. We again thank our Editorial Board and additional reviewers, as well as the Board of Trustees, the Executive Board, and the Council of IFSO for their faith in the journal and its important obligations. We thank our authors and our readers; they enabled all of us to be students and Obesity Surgery to be our teacher. 